Article

\title{
Deformation Behavior of Recycled Concrete Aggregate during Cyclic and Dynamic Loading Laboratory Tests
}

\author{
Wojciech Sas ${ }^{1, *}$, Andrzej Głuchowski ${ }^{1}$, Katarzyna Gabryś ${ }^{1}$, Emil Soból ${ }^{2}$ and Alojzy Szymański ${ }^{2}$ \\ 1 Water Centre-Laboratory, Faculty of Civil- and Environmental Engineering, \\ Warsaw University of Life Sciences-SGGW, Warsaw 02-787, Poland; \\ andrzej_gluchowski@sggw.pl (A.G.); katarzyna_gabrys@sggw.pl (K.G.) \\ 2 Department of Geotechnical Engineering, Faculty of Civil- and Environmental Engineering, \\ Warsaw University of Life Sciences-SGGW, Warsaw 02-787, Poland; \\ emil_sobol@sggw.pl (E.S.); alojzy_szymanski@sggw.pl (A.S.) \\ * Correspondence: wojciech_sas@sggw.pl; Tel.: +48-225-935400
}

Academic Editors: Yehia M. Haddad, Liangchi Zhang and David P. Thambiratnam Received: 29 July 2016; Accepted: 8 September 2016; Published: 20 September 2016

\begin{abstract}
Recycled concrete aggregate (RCA) is a relatively new construction material, whose applications can replace natural aggregates. To do so, extensive studies on its mechanical behavior and deformation characteristics are still necessary. RCA is currently used as a subbase material in the construction of roads, which are subject to high settlements due to traffic loading. The deformation characteristics of RCA must, therefore, be established to find the possible fatigue and damage behavior for this new material. In this article, a series of triaxial cyclic loading and resonant column tests is used to characterize fatigue in RCA as a function of applied deviator stress after long-term cyclic loading. A description of the shakedown phenomenon occurring in the RCA and calculations of its resilient modulus $(\mathrm{Mr} r)$ as a function of fatigue are also presented. Test result analysis with the stress-life method on the Wohler S-N diagram shows the RCA behavior in accordance with the Basquin law.
\end{abstract}

Keywords: recycled concrete aggregate; cyclic loading; plastic strain; fatigue; resilient modulus

\section{Introduction}

The settlement of pavement is a key factor when analyzing the quality of a road. It is important to investigate not only the bearing capacity of the road construction, but also its cyclic-load counterpart [1]. The literature concerning the latter in cohesionless soils explains how natural aggregates behave [2-4]. However, most of the studies to date are carried out for short-term cyclical loadings (usually with a number of cycles below 1000) [5,6]. The purpose of conducting longer-term studies is to establish the fatigue behavior of the materials, which plays important roles when designing constructions subjected to cyclical loading [6-9].

Studies on cyclical loading of unbound soils and granular materials have been conducted previously [3-5]. However, research concerning recycled concrete aggregate (RCA), among other artificial aggregates, is still rare. Improvement of knowledge about the performance of RCA when subjected to cyclical loading can be essential for its successful application in road and foundation engineering.

The degradation mechanisms of soil are observed during triaxial undrained cyclic loading when the deviator stress $q$ is high and leads to the occurrence of a liquefaction phenomenon [10]. When the deviator stress is lower and pore pressure is generated with lower velocity, liquefaction can remain unobserved. 
The serviceability limit state is lower than the bearing capacity limit state, which is observed as a liquefaction or incremental collapse [11]. The fatigue phenomenon is observed in the cyclically-loaded soil after the hardening process. Plastic hardening in a repeated loading case can occur and results in a shakedown response of the soil skeleton. Such a mechanism can be observed when changes in effective stress $\mathrm{p}^{\prime}$ and pore pressure $\mathrm{u}$ are low [12]. During repeated loading, soil responds in three possible ways: adaptation, accommodation and ratcheting [13-16].

The adaptation response is observed when cyclic stress paths return to a new elastic state. In this case, the initially accumulated plastic strains are dissipated, and the path becomes linear. This phenomenon is exclusively observed in strain states lower than $10^{-3} \%$. In the accommodation response, also known as "plastic shakedown", the plastic strains also dissipate, but the steady state is observed as a closed hysteresis loop. In the ratcheting state, the soil accumulates plastic strains in each cycle. This leads to exceeding the soil's serviceability limit and, eventually, causing its collapse.

During ratcheting, the soil stiffness changes during the cyclical loading. This is observed as a change of the modulus on stress-strain plots $[17,18]$. If the change is negative ( $\gamma$ decreases), the phenomenon is called 'cyclic softening'. If $\gamma$ increases, it is called 'cyclic hardening'. Previous studies on construction and demolition materials (C\&D) lead to the conclusion that these materials exhibit a different response to loads than natural aggregates (NA) $[19,20]$.

$C \& D$ debris consists mostly of concrete rubble, bricks, sand, timber and metal. RCAs are produced by separating and crushing C\&Ds [21]. Despite inconsistencies during tests, RCAs generally present good performances in key factors, such as bearing capacity and shear strength, making them viable candidates for pavement sub-bases [22,23]. As artificial aggregates, RCAs have intrinsically different structure compositions than NAs. RCAs are partially composed by cement matrixes made of anhydrous cement and hydration products, which form a porous microstructure. This results in high water absorption (especially in the outer layers of RCAs, called 'attached mortar'), which is conjectured to be the reason for their lower mechanical properties when compared to NAs [24,25].

The geotechnical parameters or RCAs, such as friction angle, apparent cohesion, California Bearing Ratio (CBR) value and permeability properties, have been previously tested [26-28]. However, a careful characterization of strain development during cyclic or dynamic loading in RCAs remains a challenge. To tackle this problem, in this article, the results of long-term cyclic triaxial and torsional shear tests are presented. The experiments were performed in order to the estimate resilient modulus value $M r$, which is part of the design process in the Mechanistic Empirical Pavement Design Guide [29-32]. The main aim of the present study is to characterize the permanent strain behavior and fatigue of RCAs by analyzing their moduli change.

\section{Materials and Methods}

\subsection{Material and Sample Preparation}

The RCA used in this work was obtained from the crushed concrete floor of an industrial building. The strength class of concrete was estimated at B20 (C16/20). The RCA consisted of 100\% crushed concrete $\left(\Sigma\left(R_{b}, R_{g}, X\right) \leq 1 \% \mathrm{~m} / \mathrm{m}\right)$, in accordance with European Union standards (EN 933-11:2009, 33).

\subsection{Physical Properties Analysis}

In order to estimate the physical properties, the sieve analysis was done during the first stage of the physical tests. The tests were performed according to Polish technical norm PKN-CEN ISO/TS 17892-4:2009.

A 3-layer Proctor test was performed, with 55 blows to each layer, in accordance to the Polish national standard PN-88/B-04481. The selected method is characterized by the use of a $2.5-\mathrm{kg}$ hammer and a $2.2-\mathrm{dm}^{3}$ mold. This procedure creates constant energy of compaction, whose level is equal to $0.59 \mathrm{~J} / \mathrm{cm}^{3}$. 


\subsection{The Static Tests}

Laboratory bearing capacity analysis was conducted in order to determine the engineering properties of the RCA used in road applications. This was done by performing the California Bearing Ratio (CBR) (ASTM D1883-87, 34) and direct shear tests.

CBR tests were performed with the Proctor method. Preliminary results highlighted the maximum dry density and optimum moisture content of the samples. The experiments were repeated three times for each optimum moisture content level.

The direct shear tests (DST) were conducted in a cubic shear of a side of $250 \mathrm{~mm}$. The shear box consisted of two parts a stationary bottom and a moveable top. Fully self-contained hydraulic pressure cylinders with changeable speeds (ranging from $0.01 \mathrm{~mm} / \mathrm{min}$ to $1.0 \mathrm{~mm} / \mathrm{min}$ ) generated normal and shear forces on the top part. During the tests with RCA, the velocity applied to the top of the shear box was of $0.01 \mathrm{~mm} / \mathrm{min}$ in order to avoid missing peak stress values.

The compaction of the RCA was conducted for the material with moisture contents close to its optimal value. The process was carried out in a shear box with $0.59 \mathrm{~J} \cdot \mathrm{cm}^{-3}$ compaction energy. This was done in order to prevent grain crushing and, therefore, changes in particle size distribution. Standard stress values were loaded on top of the shear box. The tests were conducted subsequently after vertical displacements reached a constant value. On top of the sample, a linear variable differential transformer (LVDT, GDS, Hampshire, UK) was installed. When the LVDT records showed no further changes in the sample height, the DSTs were performed. The experiments were terminated once the horizontal shear strains reached $9 \%$ or a visible peak and residual values in shear strength were recorded.

\subsection{Torsional Shear Test}

Torsional shear (TS) tests were performed in a resonant column apparatus (RC, GDS, Hampshire, UK). The RC and TS apparatuses used in this work were a Stokoe apparatus (GDS, Hampshire, UK) for a fixed-free configuration provided by GDS instruments [32]. After the samples reached the saturation stage, isotropic consolidation with a radial stress of $45 \mathrm{kPa}$ was performed. During TS tests, the sample was subjected to small cyclical torsional motion due to a coil-magnet system at the RC. The shear stress was calculated by the torque generated this way. The shear strain levels were determined from the twist angle of the soil sample, as measured by a proximitor. The shear strain was controlled by applying a voltage between $0.004 \mathrm{~V}$ and $1 \mathrm{~V}$ to the coils, which generated a shear strains between $0.0001 \%$ and $0.003 \%$.

The TS tests were conducted with the application of a sinusoidal load wave with frequencies of $0.1,1$ and $10 \mathrm{~Hz}$. The shear modulus $G$ and damping ratio $D$ were estimated for all three frequencies. For measurements at $0.1 \mathrm{~Hz}$ and $1 \mathrm{~Hz}$, ten cycles were taken into account for $G$ and $D$ calculations. For the $10-\mathrm{Hz}$ frequency, 100 cycles were used. The range of the tested amplitudes varied between $0.005 \mathrm{~V}$ and $0.6 \mathrm{~V}$.

\subsection{Static and Long-Term Cyclic Triaxial Tests}

Triaxial tests were carried out with a triaxial apparatus from GDS instruments (GDS, Hampshire, UK). The device was designed for cylindrical soil specimens of $7 \mathrm{~cm}$ in diameter and $14 \mathrm{~cm}$ in height. Samples were fully saturated, and a B-value greater than 0.90 was assured at each measurement. Samples were then subjected to isotropic effective confining pressures of $45 \mathrm{kPa}$ and $90 \mathrm{kPa}$ (and $225 \mathrm{kPa}$ for the static test) and consolidated. The static triaxial tests were conducted under a strain-controlled regime. The cyclic-test procedure consisted of applying an average deviator stress value $q_{m}$ superimposed to a forward-moving pulsating sine wave with constant stress amplitude $q_{a}$. The parameters of the S-N curves ( $\mathrm{S}$ stands for stress-repetitive load and $\mathrm{N}$ stands for number of cycles to failure) are presented in Figure 1. Details of the applied loading are shown in Table 1. Repeated loading triaxial tests were conducted in the consolidated-undrained (CU) conditions. 
The frequency used during the test was $1.0 \mathrm{~Hz}$. The cyclic stresses and initial confining pressure levels shown were used to define the effects of cyclic loading on soil behavior.

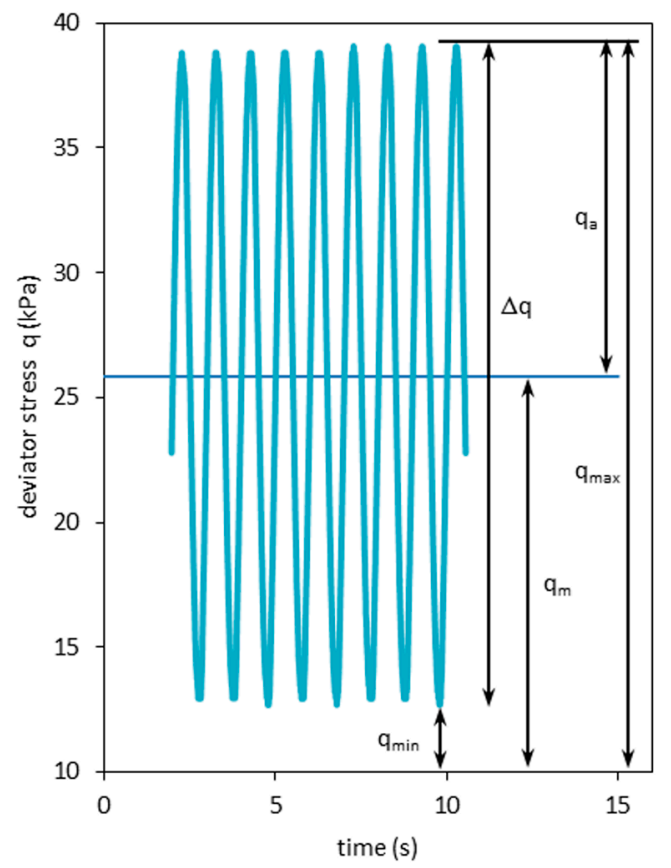

Figure 1. Stress parameters for a constant amplitude of loading for the tested recycled concrete aggregate (RCA). $q_{a}$, stress amplitude; $q_{m}$, average stress; $\Delta q$, stress difference; $q_{\text {max }}$, maximal stress; $q_{\text {min }}$, minimal stress.

Table 1. The stress parameters for the S-N curve for the tested RCA.

\begin{tabular}{cccccc}
\hline Caption & $\boldsymbol{\Delta} \boldsymbol{q}(\mathbf{k P a})$ & $\boldsymbol{q}_{\boldsymbol{m}}(\mathbf{k P a})$ & $\boldsymbol{q}_{\min }(\mathbf{k P a})$ & $\boldsymbol{q}_{\max }(\mathbf{k P a})$ & $\boldsymbol{q}_{\boldsymbol{a}}(\mathbf{k P a})$ \\
\hline Test 1.1 & 25.85 & 25.87 & 12.95 & 38.8 & 12.93 \\
Test 1.2 & 129.39 & 78.21 & 13.51 & 142.9 & 64.7 \\
Test 1.3 & 178.54 & 104.34 & 15.07 & 193.61 & 89.27 \\
Test 2.1 & 5.46 & 26.11 & 23.38 & 28.84 & 2.73 \\
Test 2.2 & 25.72 & 51.94 & 38.98 & 64.7 & 12.96 \\
Test 2.3 & 99.78 & 128.91 & 79.01 & 178.79 & 49.9 \\
\hline
\end{tabular}

\section{Results and Discussion}

\subsection{Results of Physical Tests}

Sieve test results for the RCA are shown in Figure 2a. According to [33], they account for the material being classified as a sandy gravel (saGr). The distribution of particles from $0.06 \mathrm{~mm}$ to $10 \mathrm{~mm}$ conforms to the standard for soils used in the support structures. The extracted coefficients of uniformity $(\mathrm{Cu})$ and of curvature $(\mathrm{Cc})$ amounted to 9.1 and 2.6, respectively, which classifies the RCA as a medium-graded material [34].

Results of the Proctor test are presented in Figure $2 \mathrm{~b}$. The optimum moisture content was found at $9.6 \%$, and the maximal dry density under these conditions was $1.94 \mathrm{~g} / \mathrm{cm}^{3}$. The optimal moisture content and energy of compaction were rescaled at each test stage to obtain uniform boundary conditions for the material properties. 


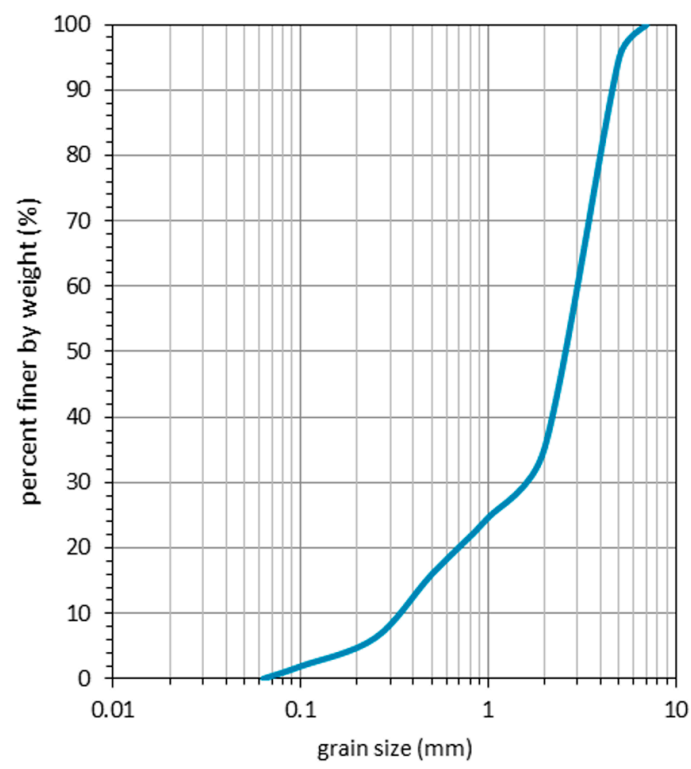

(a)

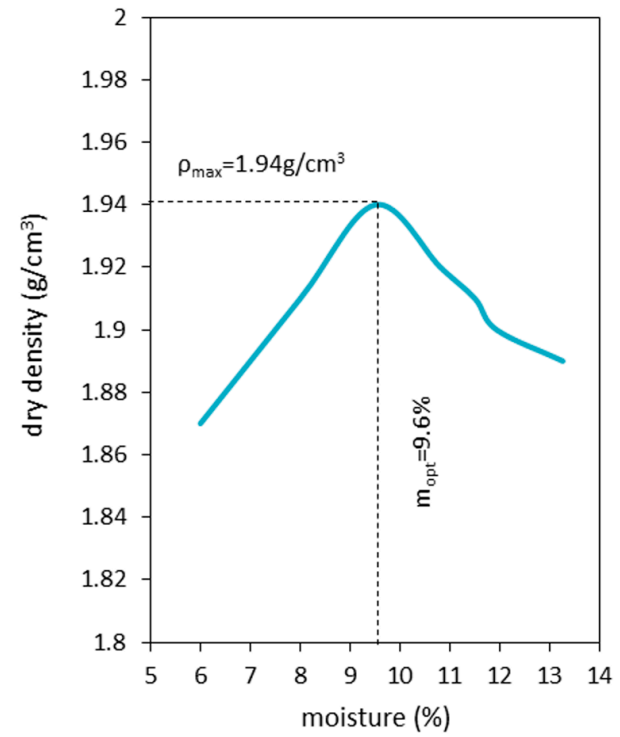

(b)

Figure 2. Results for the (a) soil gradation curve and (b) Proctor test for the experimented RCA.

\subsection{Results of Static Tests}

As a material with potential application in pavement engineering, RCAs are expected to have high CBR values. The Polish technical standards for motorways state that the CBR value for subgrade constructed from unbound aggregates should be greater than $80 \%$. The CBR tests performed on the RCA during this study are presented in Figure 3a. Experiments were carried out in samples with optimal moisture content. Results for plunger penetrations of $2.5 \mathrm{~mm}$ and $5 \mathrm{~mm}$ were calculated, ranging from $71.7 \%$ to $101.5 \%$ for $2.5 \mathrm{~mm}$ and $91.3 \%$ to $100.4 \%$ for $5 \mathrm{~mm}$. Such range differences are attributed to grain crushing and a proper contact zone between the plunger and sample surface. Natural sandy gravels are characterized by CBR values equal to $71 \%$, which places the RCA studied here in the lowest result range for subbase material [31,35].

The DST test were carried out trice under normal stress conditions of $51.5 \mathrm{kPa}, 70.2 \mathrm{kPa}$ and $83.5 \mathrm{kPa}$. The maximal shear stresses obtained under such conditions were equal to $42.6 \mathrm{kPa}, 57.7 \mathrm{kPa}$ and $69.0 \mathrm{kPa}$, respectively. Results are shown in Figure $3 \mathrm{~b}$. The estimated friction angle $\varphi$, obtained from the slope in the graphic (see Figure $3 \mathrm{~b}$ ), was estimated at $\varphi=39.5^{\circ}$. The tests did not allow one to obtain the cohesion parameter $c$. Friction angles and cohesion coefficients of natural aggregates with $\mathrm{C}_{\mathrm{U}}=6.6$ and a grain size distribution similar to the RCAs studied here were previously found to be around $\varphi=39.6^{\circ}$ and $c=0$ (see [36,37]). Studies on sandy gravel subjected to triaxial compression led to the estimation of the friction angles in the range $39^{\circ}<\varphi<48^{\circ}$ to NAs, depending on the relative density changes during the consolidation step [38].

Static triaxial test results are presented in Figure 4. Stress-strain curves are plotted in Figure 4a and show similar behavior under different confining pressures. The deviator stresses reach maximal values at axial strains of, approximately, 2.9\%, 3.4\% and $4.3 \%$ for confining pressures of $45 \mathrm{kPa}, 90 \mathrm{kPa}$ and $225 \mathrm{kPa}$, respectively. These maximal values are defined as drained shear strength and are presented in Table 2. It is seen in Figure $4 \mathrm{~b}$ that effective stress paths in drained conditions form a critical state line, which is characterized by a slope $M\left(M=q_{\max } / p^{\prime}\right.$ where $p^{\prime}=1 / 3\left(\sigma^{\prime} 1+2 \sigma 3^{\prime}\right)$ and $\left.q_{\max }=\left(\sigma^{\prime}{ }_{\max }-\sigma 3^{\prime}\right)\right)$. Such a slope relates to the effective friction angle $\varphi^{\prime}$ according to $M=\left(6 \sin \varphi^{\prime}\right) /\left(3-\sin \varphi^{\prime}\right)$. The slope of the critical state lines in Figure $4 \mathrm{~b}$ amount to 2.17, which corresponds to a friction angle of $53^{\circ}$. 


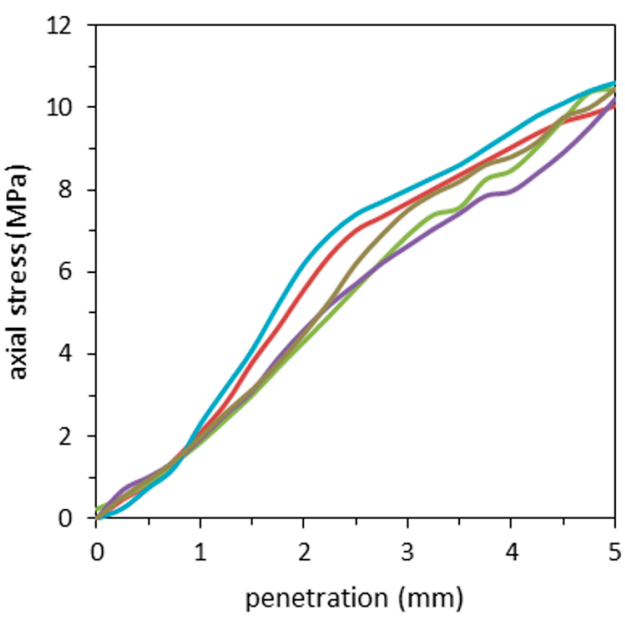

(a)

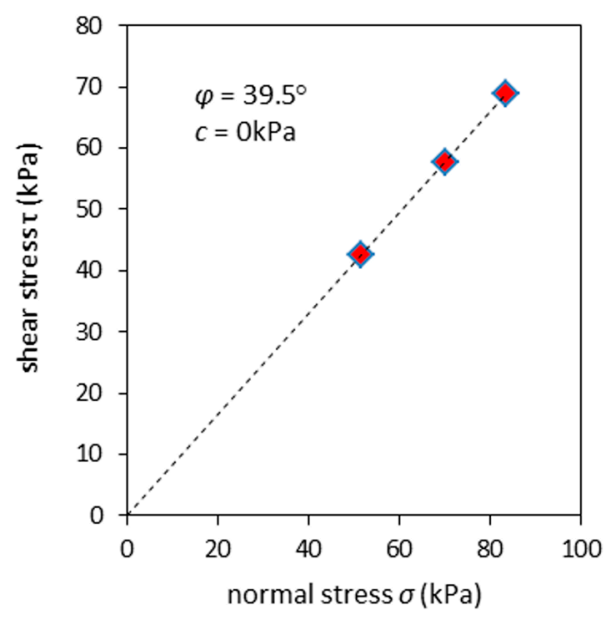

(b)

Figure 3. Results of static tests on RCA: (a) the California Bearing Ratio (CBR) test results and (b) the direct shear test (DST) results.

Table 2. The test results of the drained static triaxial tests.

\begin{tabular}{ccc}
\hline Test No. & $\boldsymbol{\sigma} \mathbf{3}^{\prime}{ }^{\prime}$ Effective Minor Axial Stress Value (kPa) & Deviator Stress at Failure (kPa) \\
\hline S.1 & 45.0 & 251.0 \\
S.2 & 90.0 & 661.0 \\
S.3 & 225.0 & 1346.0 \\
\hline
\end{tabular}

Coulomb-Mohr plots are presented in Figure 4c. The analysis of these static triaxial tests allows independent estimation of the friction angles and apparent cohesion parameters at $\varphi^{\prime}=42^{\circ}$ and $c=45 \mathrm{kPa}$, in accordance with previous studies [38]. The differences between the results arising from the effective stress plot (Figure 3b) and the Coulomb-Mohr analysis (Figure 4c) happen due to the nonlinear results of triaxial tests. The RCA structure, which involves high roughness of the grain surface, undergoes higher friction forces at lower confining pressures. On the other hand, the soil density after consolidation increases together with the effective stress. A higher effective stress results in a lower impact of grain surface roughness, which creates uncertainties in the estimation of the sample's mechanical parameters.

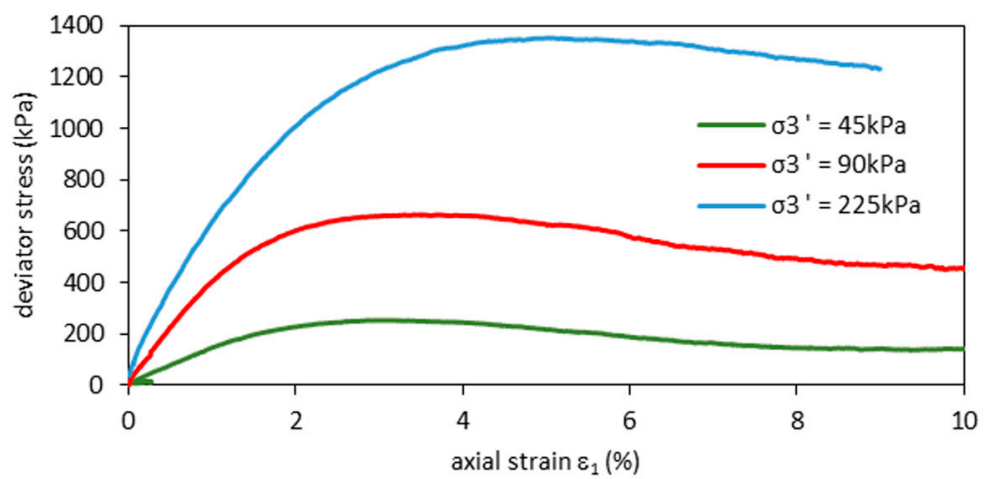

(a)

Figure 4. Cont. 


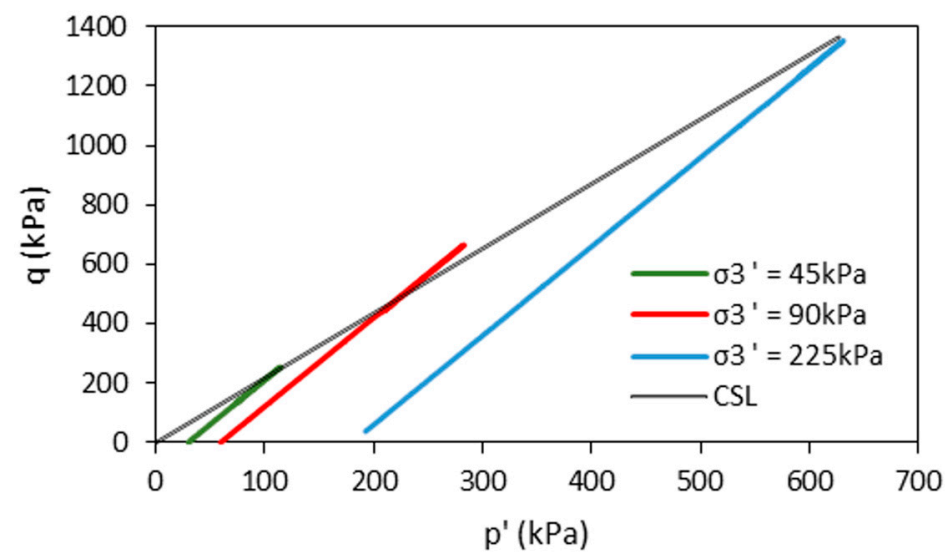

(b)

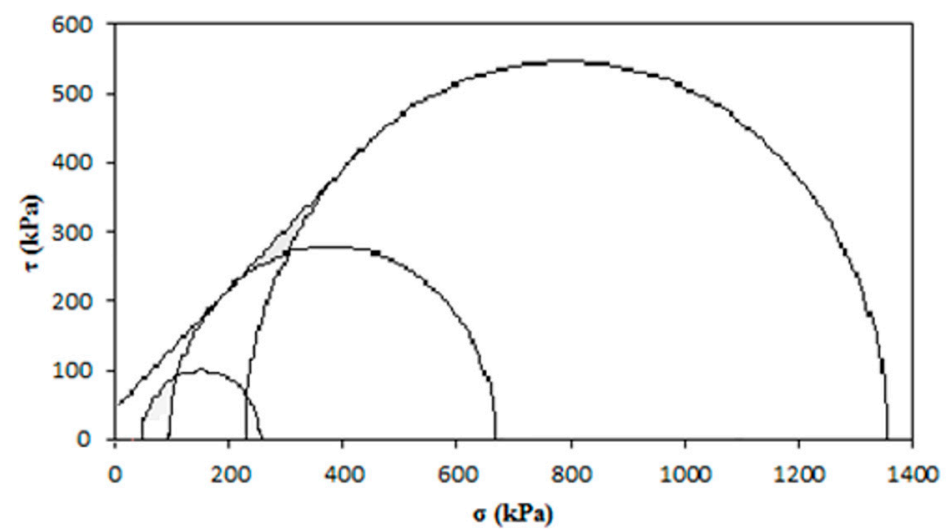

(c)

Figure 4. Results of static triaxial tests on RCA: (a) stress-strain curves; (b) effective stress paths and (c) Mohr-Coulomb effective failure envelope.

\subsection{Results of Torsional Shear Tests}

TS tests were performed in order to estimate characteristic values of the shear modulus $G$ and damping ratio $D$. The tested frequencies ranged from dynamical $(10 \mathrm{~Hz})$ to quasi-static loadings $(0.1 \mathrm{~Hz})$. Results are presented in Table 3.

Table 3. Shear modulus and damping ratio of the tested material.

\begin{tabular}{ccc}
\hline Freq. (Hz) & $\boldsymbol{D}_{\min }(\%)$ & $\boldsymbol{G}_{\max }(\mathbf{M P a})$ \\
\hline 0.1 & 1.61 & 55 \\
1 & 1.83 & 60 \\
10 & 3.1 & 56 \\
\hline
\end{tabular}

The normalized shear modulus $\left(G / G_{\max }\right)$ and normalized damping ratio $\left(D / D_{\min }\right)$ at different frequencies $f$ are shown as a function of $\gamma$ in Figures 5 and 6 . The results show the low dependence of $G / G_{\max }$ and $D / D_{\min }$ on the frequency value. The values of the low-amplitude shear modulus $\left(G_{\max }\right)$ and damping ratio $\left(D_{\min }\right)$ are lower than the shear modulus and damping ratio at higher frequencies (see Table 3). With increasing $f, G_{\max }$ values rise between $9 \%$ (for $f=1 \mathrm{~Hz}$ ) and $2 \%$ (for $f=10 \mathrm{~Hz}$ ) with respect to the $G_{\max }$ value for $f=0.1 \mathrm{~Hz}$. The $G_{\max }$ and $D_{\min }$ values characterize the low dispersion of points, and that suggests that their increase is linear in $f$. 


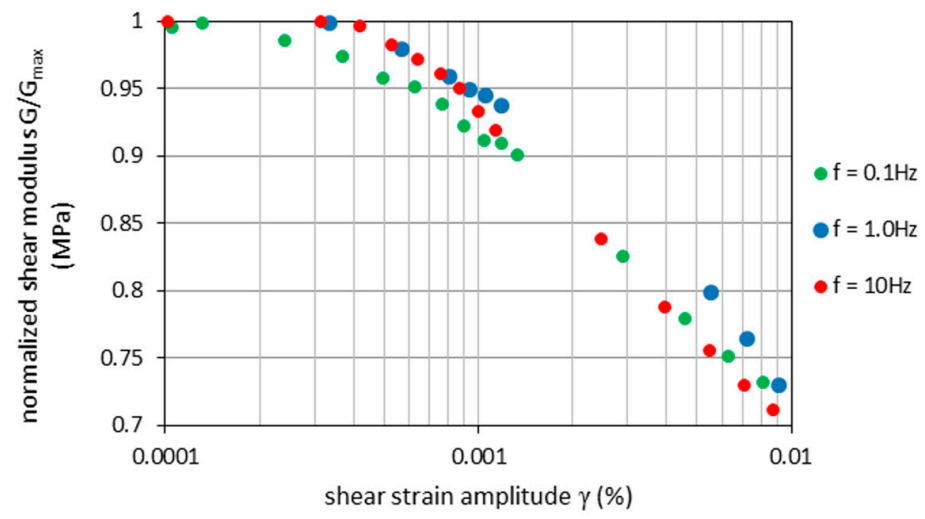

Figure 5. Normalized shear modulus $G / G_{\max }$ versus shear strain amplitude for isotropicallyconsolidated RCA $\left(\sigma 3^{\prime}=45 \mathrm{kPa}\right)$ for various test frequencies.

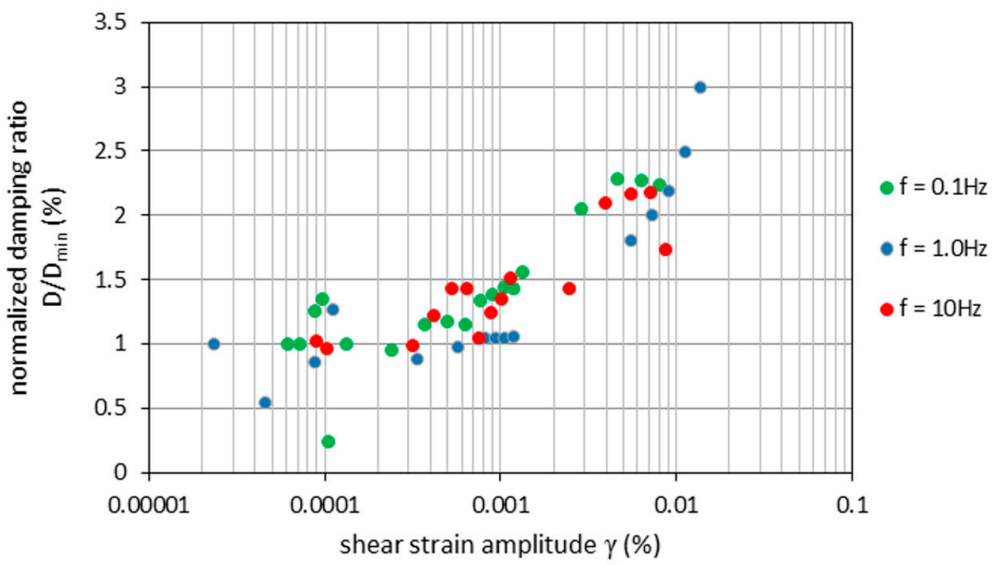

Figure 6. Normalized damping ratio $D / D_{\min }$ versus shear strain amplitude for isotropicallyconsolidated RCA $\left(\sigma 3^{\prime}=45 \mathrm{kPa}\right)$ for various test frequencies.

\subsection{Cyclic Triaxial Test Results}

The cyclic triaxial tests were performed under a deviator stress $q_{\max }=38.8 \mathrm{kPa}$. DST results showed a friction angle $\varphi=39.5^{\circ}$. Maximal deviator stresses $q_{\max }$ were calculated from:

$$
\sigma \prime_{1}=\sigma \prime_{3} \cdot \tan ^{2}\left(45+\frac{\varphi}{2}\right)
$$

where $\sigma \prime_{1}=q+\sigma \prime_{3}$ is the effective major axial stress and $\sigma \prime_{3}$ corresponds to the effective minor axial stress value; in order to do so, Formula (1) can be rewritten to: $q_{\max }=\sigma_{3}^{\prime}\left(\tan ^{2}\left(45+\frac{\varphi}{2}\right)-1\right)$. The values obtained this way for $q$ were $q=257.3 \mathrm{kPa}$ (for $p_{0}^{\prime}=45 \mathrm{kPa}$ ) and $q=314.6 \mathrm{kPa}$ (for $p_{0}^{\prime}=90 \mathrm{kPa}$ ). The applied deviator stresses during cyclic loading tests were, therefore, a fraction of $q_{\max }$.

During the first test stage, which occurred for effective stress $p_{0}^{\prime}=45 \mathrm{kPa}$, the maximal deviator stresses $q_{\max }$ were equal to $38.8 \mathrm{kPa}, 142.9 \mathrm{kPa}$ and $193.61 \mathrm{kPa}$. These values correspond to $15 \%$, $55 \%$ and $75 \%$ of $q\left(p^{\prime}=45 \mathrm{kPa}\right)$, respectively. In the second loading stage, $p^{\prime}{ }_{0}=90 \mathrm{kPa}$, the maximal deviator stress $q_{\max }$ was equal to $28.84 \mathrm{kPa}, 64.70 \mathrm{kPa}$ and $178.79 \mathrm{kPa}$, corresponding to $10 \%, 20 \%$ and $57 \%$ of $q\left(p_{0}^{\prime}=90 \mathrm{kPa}\right)$, respectively.

Figure 7 shows the effective $\mathrm{p}^{\prime}$ stress paths obtained during each test. These plots clearly show different mean effective stress paths during cycling, providing a tool to analyze the stress-path evolution. Such evolution happens as a result of pore pressure generation, with particle crushing after numerous cycles causing a steady decrease of the excess pore pressure. This is observed as a slower 
increase of the effective stress path. In addition, the figures show that the maximal stress $q_{\max }$ and the stress amplitude $q_{a}$ are greatly affected by changes in $p_{0}^{\prime}$.

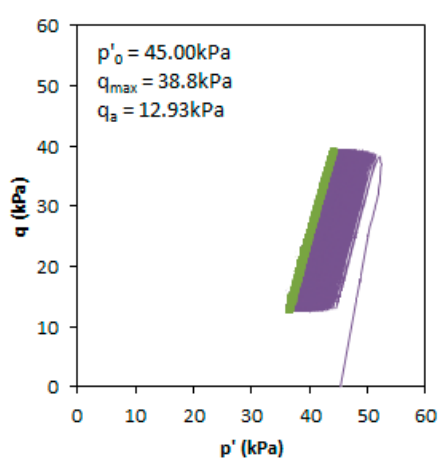

(a)

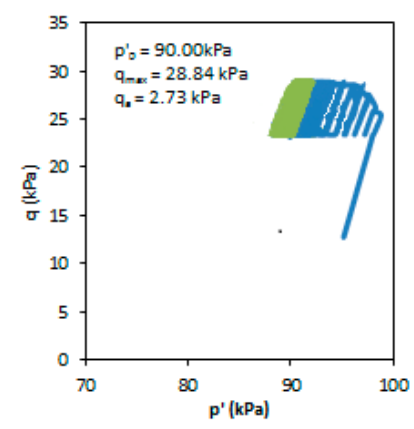

(d)

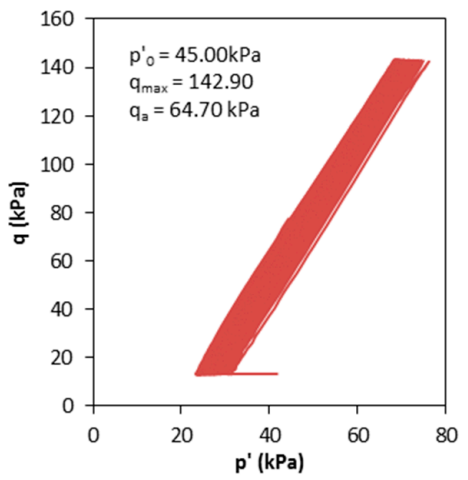

(b)

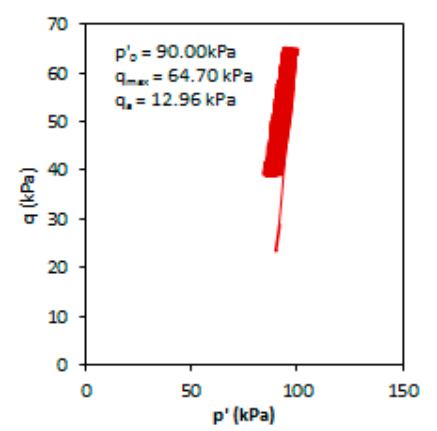

(e)

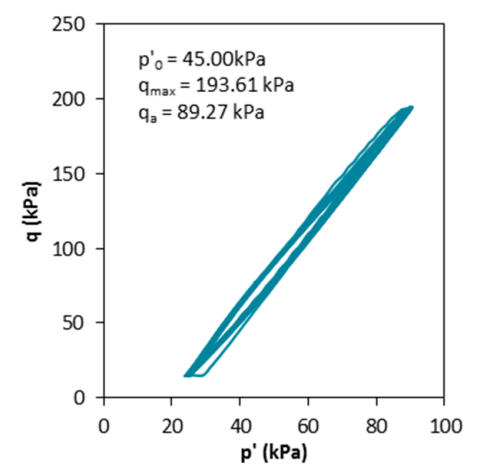

(c)

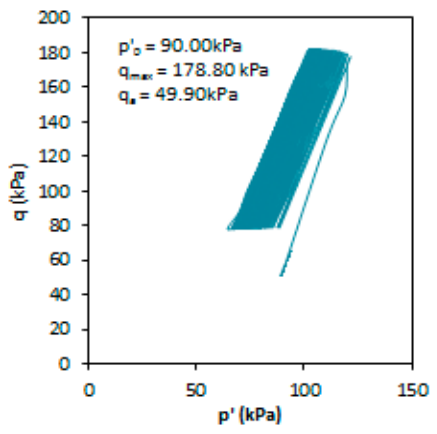

$(\mathbf{f})$

Figure 7. Stress paths for different test conditions: (a) 1.1 ; (b) 1.2 ; (c) 1.3 ; (d) 2.1 ; (e) 2.2 and (f) 2.3; as defined in Table 1.

The experiments performed in undrained conditions lead to pore pressure generation. The pore pressure generation develops in the same scenario. At the beginning of each test, the excess pore water pressure rose, reaching stabilized values after approximately 100 cycles. After ca. 1000 cycles, the generation of pore pressure was constantly at low levels, in comparison with previous precedent runs. During undrained tests, the pore pressure was not expected to dissipate due to leakage. This happened because drainage was kept steady by pressure and volume controllers. However, experiments have shown otherwise (see Figure 8). The observed dissipation may be attributed to grain breakage or, at the early stages of cyclic loading, to the typical internal porosity and high water adsorption of the material characteristics for RCAs. When high stress deviators and stress amplitudes were applied, the pore pressure evolved in a different manner. The first few cycles lead to high pore pressure generation, which remained constant. This is seen in Figure 8.

In particular, for the test with $p_{0}^{\prime}=45 \mathrm{kPa}$ and $q_{\max }=38.8 \mathrm{kPa}$, the excess pore pressure rose slowly and stabilized after the 10th cycle. The same was observed for Test 2.1 (see Table 1 and Figure 8). During Tests 1.2 and 2.2, the pore pressure rose in two stages, as it did during Tests 1.1 and 2.1 (the former after the 10th cycle and the latter after the 100th cycle). However, after the 100th cycle, the velocity of pore pressure decreased slower in these tests. This can be caused by the existence of a threshold deviator stress, under which the pore pressure stabilizes itself. Nevertheless, indirect conclusions can be drawn from the analysis of the accumulation of plastic strains, which are presented in Figure 9.

The permanent strain accumulation in Tests 1.1, 2.1 and 2.2 follows the same pattern after the 100th repetition. This allows the conclusion that plastic strains are lower for smaller deviator stress amplitudes $q_{a}$. The first 100 cycles, which correspond to a process of compaction and grain movement, present a different pattern of plastic strain generation. A possible explanation for this fact lies in how 
the consolidation process was conducted. Although anisotropic consolidation, which represents a natural sedimentation environment, represents conditions found in nature, the artificial grains in RCAs may be acting differently when compared to natural aggregates.

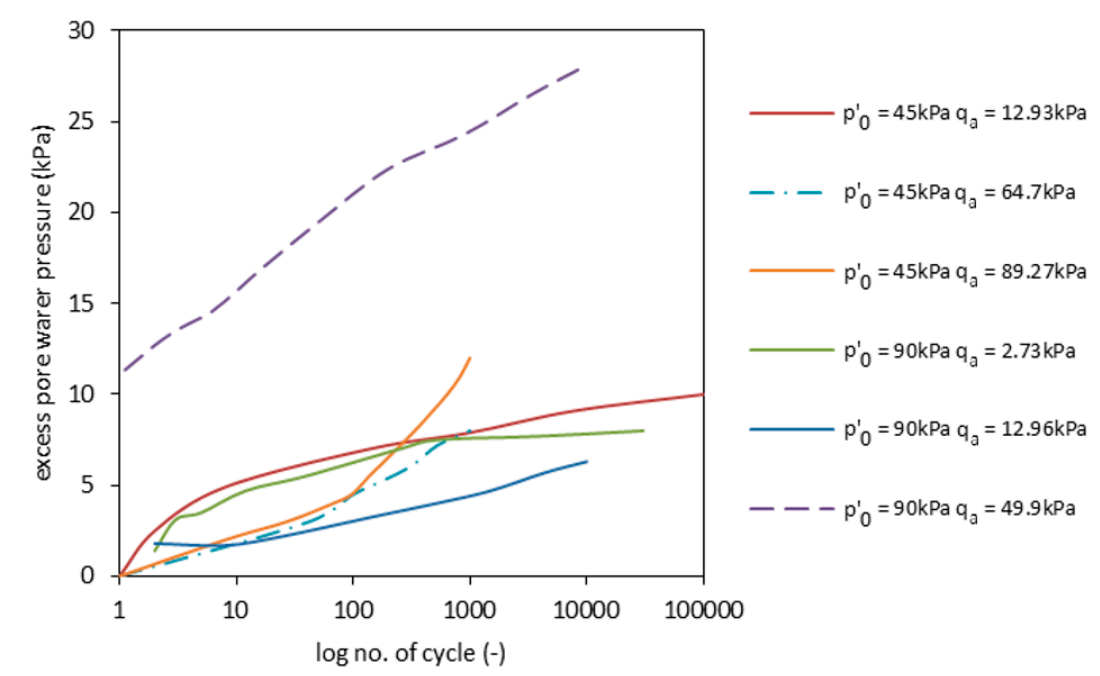

Figure 8. Excess pore pressure generation during the three tests for the RCA sample.

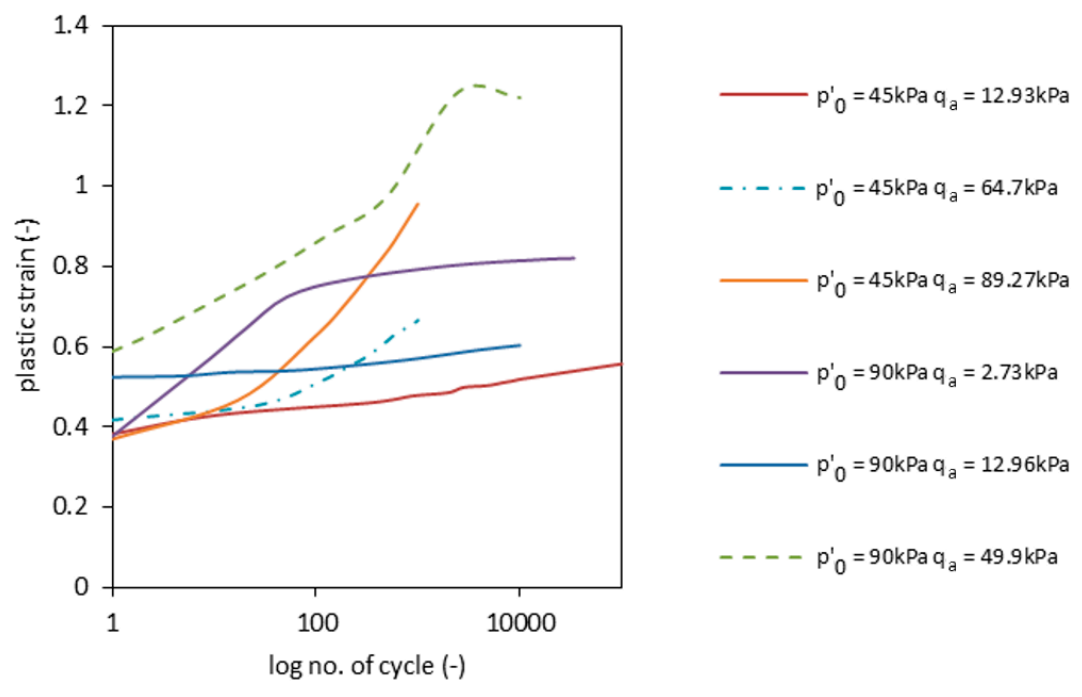

Figure 9. The accumulation of plastic strains during the three tests for the RCA sample.

In order to show the development of plastic strain during cyclical loading, selected cycles of the strain-stress chart are plotted in Figure 10. The effects of degradation in the soil properties are more evident in Figure 10a. For subsequent cycles, the stress-strain hysteresis inclination (the slope of the line connecting both ends of the hysteresis loop) is reduced. This means a decrease of sample stiffness. The degradation process starts after the plastic hardening. The plastic hardening stops when no further plastic strains are observed in one cycle. During the test, the area of the hysteresis loop was also quantified. Its increase demonstrates the occurrence of degradation (see Figure 10e).

In Figure 10b, the high plastic strain accumulation in the first few cycles is shown. These strains are observed even after the development of the unloading phase. However, after $10^{5}$ cycles, the plastic strains during cycling vanished. In the absence of plastic strains, the excess pore pressure generation also stops. This suggests that, in undrained conditions, the development of plastic axial strain is greatly influenced by the excess pore water pressure. The strain stress plots show that axial strain curves have similar shapes for the tests presented in Figure 10c-f. 

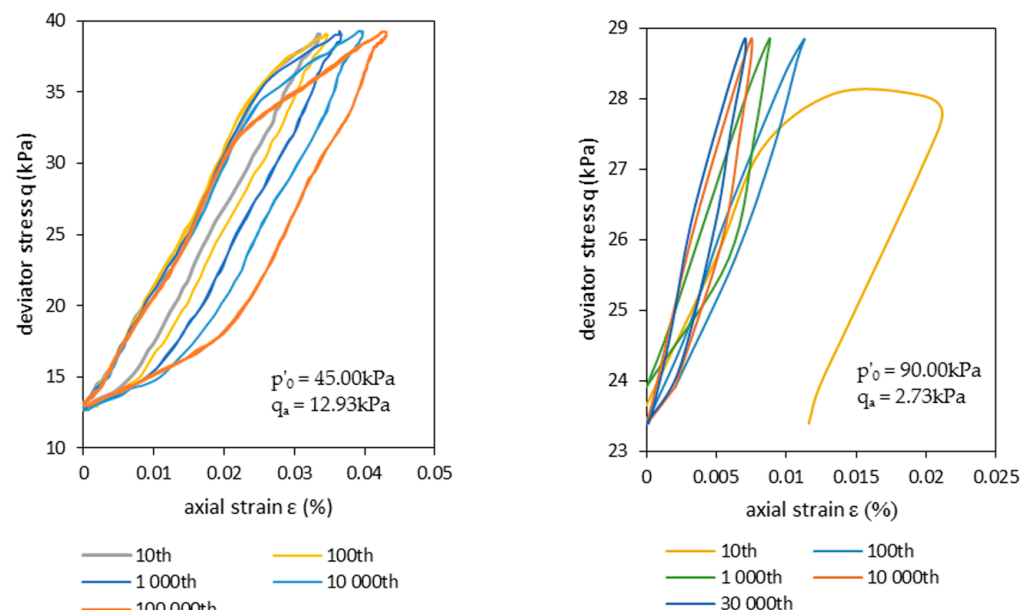

(b)
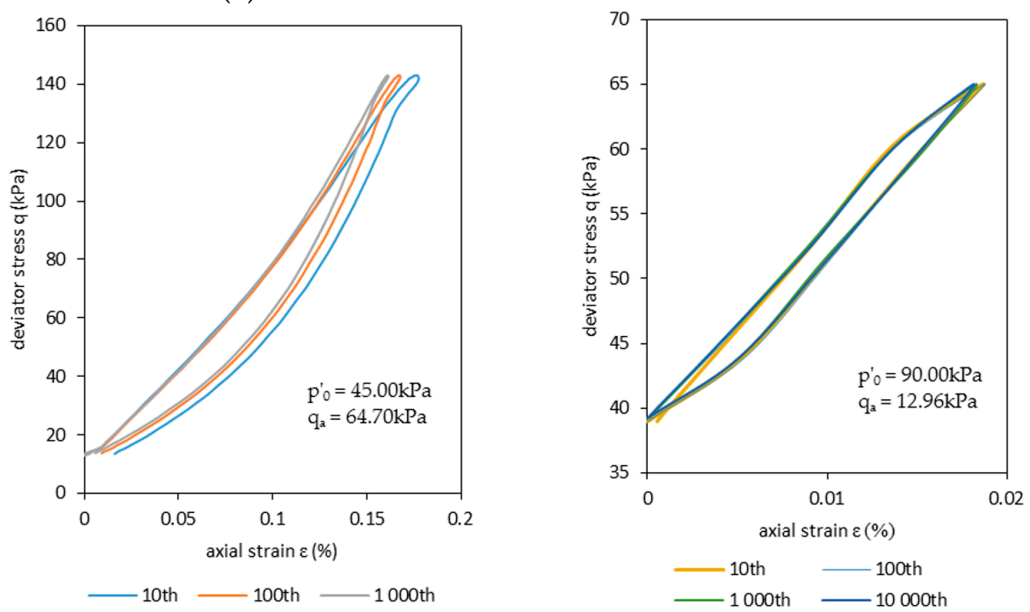

(c)

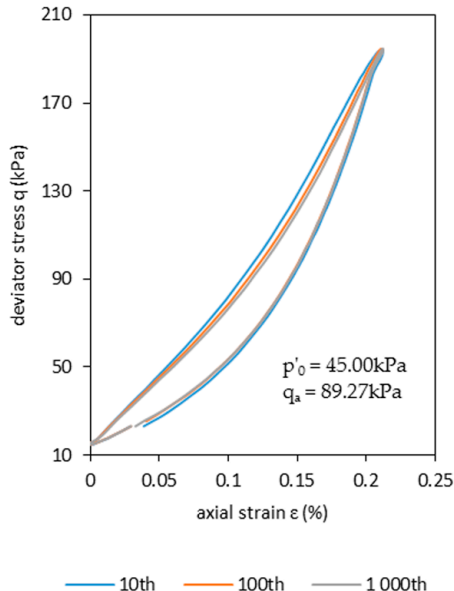

(e)

(d)

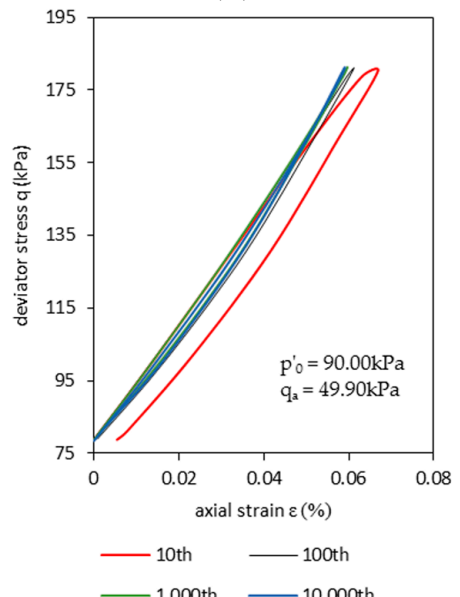

(f)

Figure 10. Stress-strain plot during three test levels on an RCA sample under different effective stresses $p_{0}^{\prime}$, as indicated in the figures (different lines correspond to different loading cycles). The panels correspond to: (a) Test 1.1; (b) Test 2.1; (c) 1.2; (d) Test 2.2; (e) Test 1.3; (f) Test 2.3.

The lower value for the deviator amplitude $q_{a}$ during Test 1.1 resulted in lower residual values of axial strain in comparison with Tests 1.2 and 1.3. For example, the values of permanent axial strain during the 1000th cycle (Figure 10e) were, approximately, 2.0- and 1.4-times smaller in Test 1.1 when compared to Tests 1.3 and 1.2, respectively. The effect of confining pressures is also clear from 
the results, with confining pressures conditioning the RCA sample to a much stiffer response to cyclical loading.

Total strains showed overall lower values for higher maximal deviator stresses $q_{\max }$. Deviator stress amplitude $q_{a}$ also has an impact on the RCA sample behavior, with lower $q_{a}$ values accounting for lower total axial strains. However, the impact of $q_{a}$ on plastic strain development seems to be insensitive to effective stress $p_{0}^{\prime}$ and maximal axial stress $q_{\max }$. This can be clearly observed in Figure 9 and when comparing Figure 10b with Figures 10d and 10c with Figure 10f.

The resilient modulus $\mathrm{Mr}$, which describes the elastic (or resilient) strain during the unloading phase in one cycle of the loading test, was calculated, for all three tests, according to:

$$
M_{r}=\frac{\Delta q}{\varepsilon_{r}} .
$$

In Equation (3), $\Delta q$ stands for the stress difference of cyclic stress $\left(\Delta q=q_{\max }-q_{\min }\right)$ and $\varepsilon_{r}$ for the resilient strain.

Calculated values for $\mathrm{Mr}$ are presented in Figure 11 and included in Table 4. In it, the maximal value obtained for $M r$ was $\max (M r)=1715 \mathrm{kPa}$. The decrease of $M r$ is characterized by the reduction of the slope in stress-strain $(q(\varepsilon))$ charts. The occurrence of stiffness degradation can be observed by using the $\mathrm{Mr}$ development plot over the number of cycles. The decrease of the resilient modulus stands for inclination growth towards the $\mathrm{X}$ axis on the stress-strain chart. This statement is only valid when no plastic strains occurs. The phenomena of plastic strain abation can be observed after the plastic hardening process. The decrease of $M_{r}$ after plastic hardening (approximately $10^{2}$ to $10^{3}$ cycles) happens due the degradation of the RCA stiffness. This was observed in all tests, except for 2.1. In the latter case (Figure 11, green dashed line), hardening still occurs after $3 \times 10^{4}$ cycles. This process leads to RCA compaction, resulting in the increase of $M r$. It is expected that, for a large enough number of cycles, maximal compaction will occur akin to the remaining curves shown here. At this point, $M r$ is expected to reach its highest value, after which the degradation phenomena should take place.

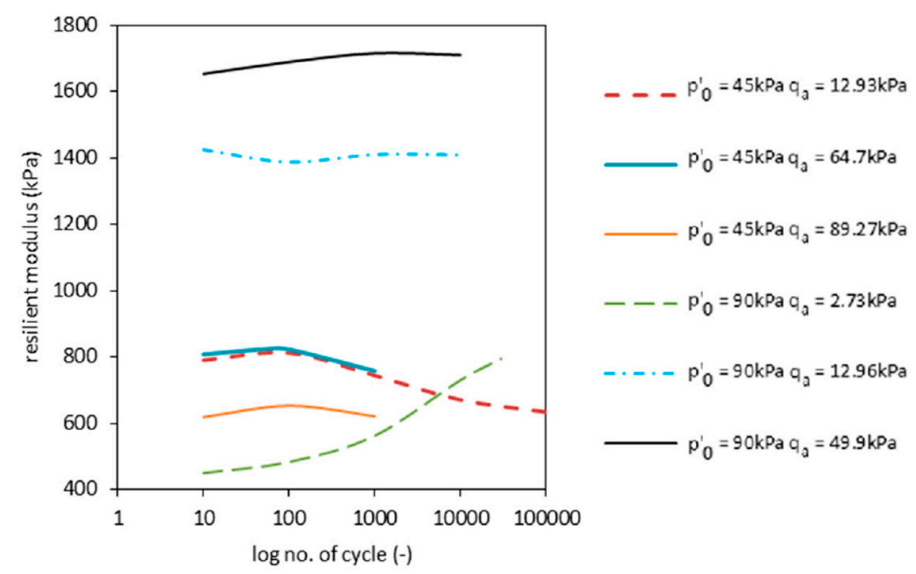

Figure 11. Resilient modulus change during the tests.

Table 4. Resilient modulus $\mathrm{Mr}$ (in $\mathrm{kPa}$ ) for selected cycles of the tested RCA.

\begin{tabular}{cccccc}
\hline No. of Test/No. of Cycle & $\mathbf{1 0}^{\mathbf{1}}$ & $\mathbf{1 0}^{\mathbf{2}}$ & $\mathbf{1 0}^{\mathbf{3}}$ & $\mathbf{1 0}^{\mathbf{4}}$ & $\mathbf{1 0}^{\mathbf{5}}$ \\
\hline 1.1 & 790 & 812 & 744 & 670 & 633 \\
1.2 & 808 & 823 & 758 & - & - \\
1.3 & 618 & 652 & 621 & - & - \\
2.1 & 450 & 483 & 562 & 730 & - \\
2.2 & 1436 & 1387 & 1410 & 1422 & - \\
2.3 & 1654 & 1689 & 1715 & 1710 & - \\
\hline
\end{tabular}


Calculations on the plastic strain accumulation $\varepsilon_{p}$ led to the estimation of the function describing the permanent strain growth as a function of the number of cycles. The function was of the type:

$$
\varepsilon_{p}=A \cdot \ln (N)-b,
$$

where $A$ and $b$ are constants of the function estimated on the basis of the 100th cycle, during which no excessive plastic strain was observed, while $N$ stands for the number of cycles. The details concerning constants $A$ and $b$ are presented in Table 5 .

Table 5. $A$ and $b$ coefficients of plastic strain growth.

\begin{tabular}{cccc}
\hline Test No. & $\boldsymbol{A}$ & $\boldsymbol{b}$ & $\boldsymbol{R}^{2}$ \\
\hline 1.1 & 0.0170 & -0.7890 & 0.992 \\
1.2 & 0.0686 & -0.3231 & 0.997 \\
1.3 & 0.1425 & -0.6649 & 0.997 \\
2.1 & 0.0120 & -0.0489 & 0.982 \\
2.2 & 0.0119 & -0.0586 & 0.997 \\
2.3 & 0.0854 & -0.3923 & 0.987 \\
\hline
\end{tabular}

The plastic strain development depends on the maximal deviator stress at failure $q_{f \max }$ (see Table 2). The coefficients $A$ and $b$ can be calculated from $q_{f \max }$ (obtained from the static triaxial tests), stress characteristic parameters and confining pressures.

The relation between $A$ and $q_{f \max }$ is governed by the $A_{f}$ parameter, which is given by:

$$
A_{f}=q_{f \max } \cdot A .
$$

The right-hand side for Equation (4) can be expanded as:

$$
\ln A_{f}=x_{1}+\frac{x_{2}}{\ln \sigma \prime_{3}}+x_{3} \cdot q_{\max }+x_{4} \cdot q_{\max }^{2}+x_{5} \cdot q_{\max }^{2} \cdot \ln q_{\max }
$$

where the coefficients $x_{1}$ to $x_{5}$ are free parameters: $x_{1}=6.349408224 ; x_{2}=-15.0083947$; $x_{3}=-0.06046039 ; x_{4}=0.002098017 ;$ and $x_{5}=-0.00033319$. The $R^{2}$ value for Equation (5) equals 0.999. A plot of Equation (5) with its corresponding experimental data is shown in Figure 12a.

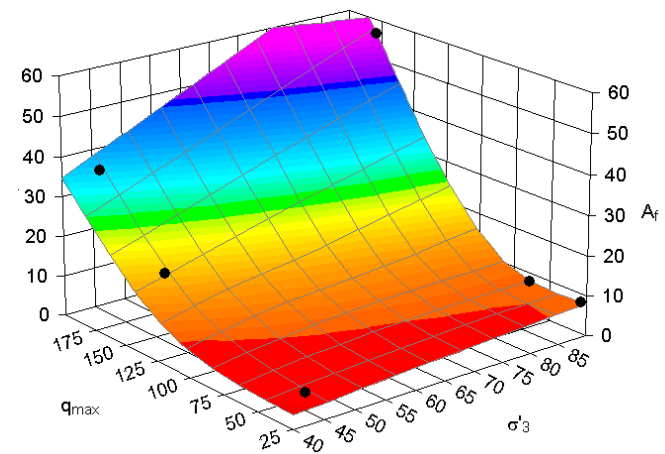

(a)

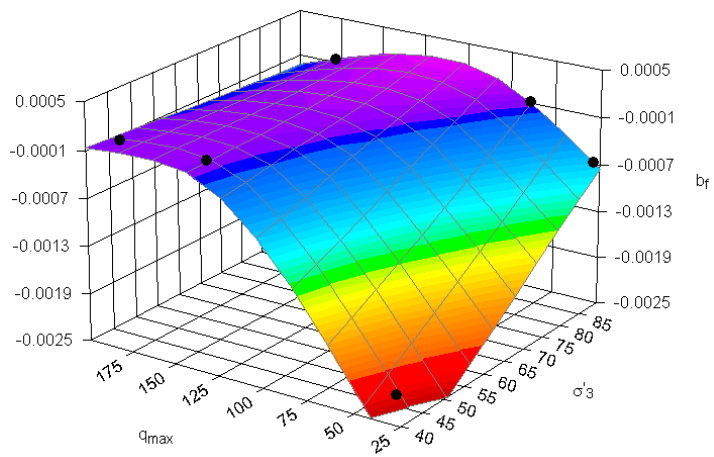

(b)

Figure 12. 3D view of (a) $A_{f}$ and (b) $b_{f}$ parameter change in various confining pressure $\sigma^{\prime}{ }_{3}$ and maximal deviator stress during cyclic loading for $q_{\max }$ values (black points stand for test results).

The parameter $\mathrm{b}_{\mathrm{f}}$ relates to $q_{f \max }, q_{a}$ and $q_{m}$ according to:

$$
b_{f}=\frac{q_{f \max } \cdot b}{q_{a} \cdot q_{m}},
$$


with $b_{f}$ given by:

$$
b_{f}=y_{1}+\frac{y_{2}}{\sigma \prime_{3}}+\frac{y_{3}}{\sigma)^{2}}+\frac{y_{4}}{q_{\max }}+\frac{y_{5}}{q_{\max }{ }^{2}} .
$$

In Equation (7), $y_{1}$ to $y_{5}$ are constants: $y_{1}=0.005293425 ; y_{2}=-0.4813725 ; y_{3}=12.19047619$; $y_{4}=-0.17492899$; and $y_{5}=-3.099584519$. The $R^{2}$ value for Equation (5) equals 0.747. A plot of Equation (7) with its corresponding experimental data is shown in Figure 12b.

The functions describing $\varepsilon_{p}$ presented $R^{2}$ higher than 0.98 for all corresponding experiments (see Table 5). The calculations of plastic strain were later employed to calculate the number of cycles until the failure $\left(N_{f}\right)$, which represents the largest strain predicted to occur in a designed structure. These results formed the basis of the stress-life method in the Wohler S-N diagram. The S-N diagram shows the stress amplitude $S_{a}$ as a function of the number of cycles, until the occurrence of the failure at $N_{f}$. Results are presented in Figure 13.

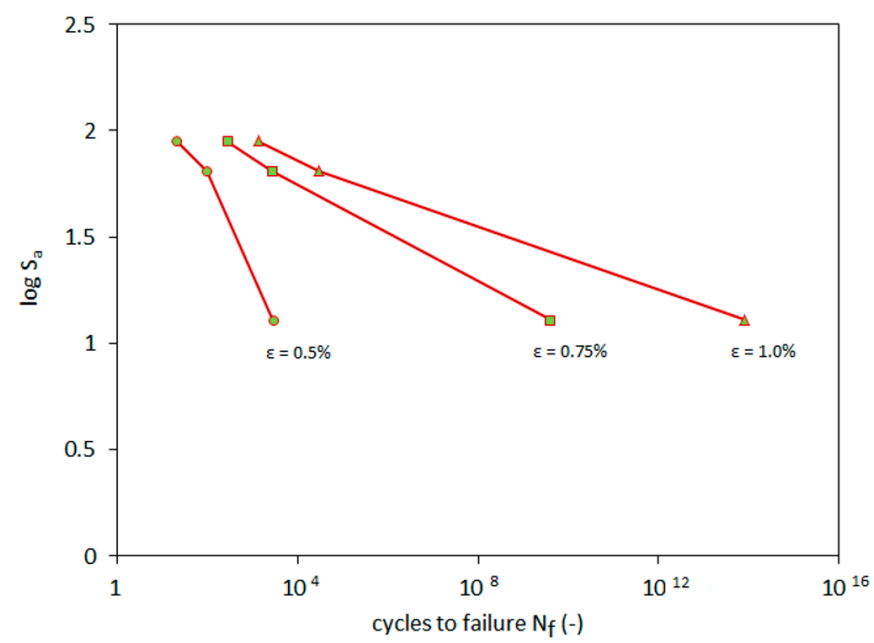

(a)

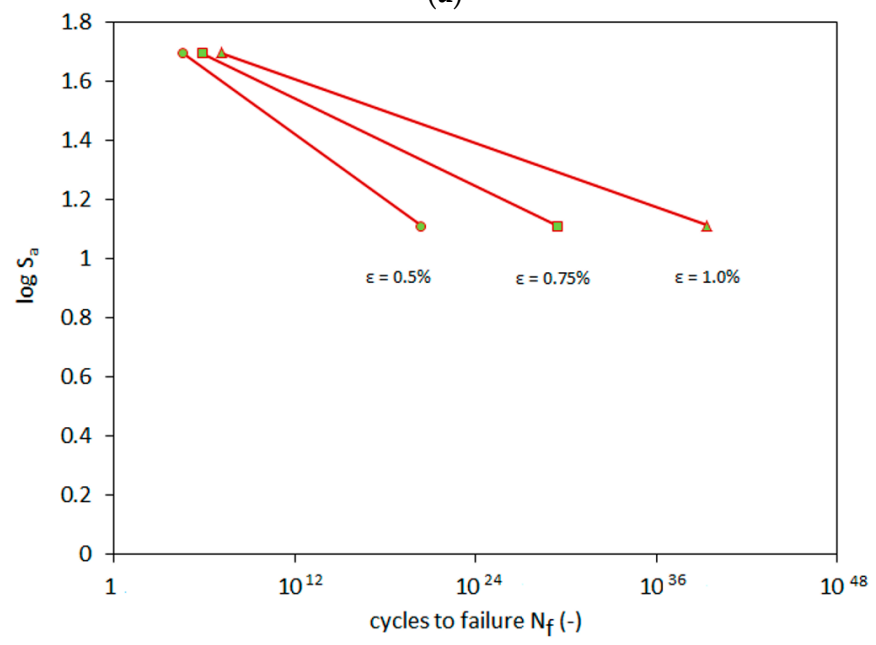

(b)

Figure 13. S-N plots for the RCA in various strain to failure conditions at effective stresses of (a) $p^{\prime}=$ $45 \mathrm{kPa}$ and (b) $p^{\prime}{ }_{0}=90 \mathrm{kPa}$.

The plot of the S-N relationship in a log-log scale clearly indicates the power relationship of this characteristic, which can be observed as a straight line in Figure 13. This phenomenon refers to the Basquin proposition of the log-log strain line in the S-N relationship, confirming this phenomenon. 
The S-N relation is well described by:

$$
\log \left(S_{a}\right)=C \cdot N_{f}^{d}
$$

with $C$ and $d$ adjustable free parameters. Their values for all tests are shown in Table 6 .

Table 6. Coefficients $C$ and $d$ of the Basquin proposition of the strain line in the S-N relationship.

\begin{tabular}{ccccc}
\hline \multirow{2}{*}{ Caption } & \multicolumn{2}{c}{$45 \mathbf{k P a}$} & \multicolumn{2}{c}{$90 \mathbf{k P a}$} \\
\cline { 2 - 5 } & $C$ & $d$ & $C$ & $d$ \\
\hline$\varepsilon=0.5 \%$ & 1.917 & -0.012 & 2.0537 & -0.008 \\
$\mathcal{E}=0.75 \%$ & 1.8849 & -0.008 & 2.051 & -0.007 \\
$\varepsilon=1.0 \%$ & 1.864 & -0.006 & 2.0518 & -0.006 \\
\hline
\end{tabular}

The results of the calculations show that the increase of the allowed design strains also raises the number of fatigue cycles. During the first phases of loading, plastic strain accumulations become more prominent. This results in earlier cycles having greater impact on the fatigue criterion. Therefore, the RCA material should be preloaded numerous times by the maximal designed stress during the project-building phase. This should prevent major plastic strains at the beginning of the exploitation phase of the construction. The RCA behaves in accordance with the Basquin law. The characteristic 'knee', which can be observed in other materials, was not observed during the RCA tests.

\section{Conclusions}

In the present article, a series of tests on recycled concrete aggregate were conducted. The results of this study lead to the following conclusions:

1. CBR test results ranged between $71.7 \%$ and $101.5 \%$ for a $2.5-\mathrm{mm}$ plunger depth and between $91.3 \%$ and $100.4 \%$ for $5.00 \mathrm{~mm}$. These results fulfill the standards necessary to classify RCAs as a subbase layer application.

2. DSTs allowed an estimation of the friction angle $\varphi=39.5^{\circ}$, while not allowing a proper observation of the cohesion $c$. Static triaxial test results provided effective friction angle $\varphi^{\prime}=42^{\circ}$ and apparent cohesion $c=45 \mathrm{kPa}$. The differences are caused by the RCA structure, which involves high roughness of the grain surface.

3. Torsional shear tests allowed establishing the value of the shear modulus $G_{\max }$ and damping ratio $D_{\min }$ for $f=1 \mathrm{~Hz}$ at approximately $G_{\max }=60 \mathrm{MPa}$ and $D_{\min }=1.83 \%$.

4. During the tests, excessive pore water pressures were observed. They started to stabilize after ca. 100 cycles, reaching steady low levels after approximately 1000 cycles.

5. During the experiments, a change of the area of the hysteresis loops $q x \varepsilon$ was observed. This was clearly observed during Test 1.1. The resilient modulus $\mathrm{Mr}$ also presented a decrease during the test. The decrease of $M r$ after the plastic hardening process (approximately $10^{2}$ to $10^{3}$ cycles) is interpreted as a consequence of the degradation of RCA stiffness. This phenomena was observed in all tests, except Test 2.1. In the latter, the RCA showed hardening even after $3 \times 10^{4}$. The overall maximal obtained $M r$ was equal to $1715 \mathrm{kPa}$.

6. An empirical formulas (Equations (4)-(7)) for permanent strain development as a function of $N$, $\sigma^{\prime}{ }_{3}, q_{\max }$ and $q_{f \max }$ has been established. Predicted permanent strains based on these formulas agree well with the test results.

7. Results were interpreted based on the stress-life method in the Wohler S-N diagram. The S-N diagram plots the stress amplitude $q_{a}$ versus cycles until the occurrence of the failure $N_{f}$. The RCA exhibits behavior in accordance to the Basquin law. The characteristic "knee", which can be observed in the case of other materials, was not observed during the tests for the RCA. 
8. Results suggest that the pore pressure development at early stages of cyclic loading is impacted by internal porosity and high water adsorption, which is characteristic for RCAs.

Acknowledgments: The discussion about the results obtained was carried out with the valuable support of Bruno Cury Camargo (LNCMI (Laboratoire National des Champs Magnetiques Intenses), Toulouse, France).

Author Contributions: Wojciech Sas and Andrzej Głuchowski prepared the manuscript and performed the cyclic triaxial tests. Emil Soból and Katrzyna Gabryś performed the TS tests. Emil Soból and Andrzej Głuchowski performed the physical and DST tests. Katarzyna Gabryś and Alojzy Szymański consulted the research program and proofread the manuscript.

Conflicts of Interest: The authors declare no conflict of interest.

\section{References}

1. Shajarati, A.; Sørensen, K.W.; Nielsen, S.K.; Ibsen, L.B. Behaviour of Cohesionless Soils During Cyclic Loading; DCE Technical Memorandum: Aalborg, Denmark, 2012.

2. Ishihara, K.; Towhata, I. Cyclic behavior of sand during rotation of principal stress axes. In Mechanics of Granular Material: New Models and Constitutive Equations; Jenkins, J.T., Satake, M., Eds.; Elsevier Science Ltd.: Philadelphia, PA, USA, 1983; pp. 53-73.

3. Tokimatsu, K.; Yamazaki, T.; Yoshimi, Y. Soil liquefaction evaluations by elastic shear moduli. Soils Found. 1986, 26, 25-35. [CrossRef]

4. Teachavorasinskun, S.; Tatsuoka, F.; Lo Presti, D.C.F. Effects of the cyclic prestraining on dilatancy characteristics and liquefaction strength of sand. In Proceedings of the Pre-failure Deformation of Geomaterials, Rotterdam, The Netherlands, 12-14 September 1994; pp. 75-80.

5. Wichtmann, T.; Niemunis, A.; Triantafyllidis, T. Strain accumulation in sand due to cyclic loading: Drained triaxial tests. Soil Dyn. Earthq. Eng. 2005, 25, 967-979. [CrossRef]

6. AnhDan, L.Q.; Koseki, J. Effects of large number of cyclic loading on deformation characteristics of dense granular materials. Soils Found. 2004, 44, 115-123. [CrossRef]

7. Gavin, K.G.; O'Kelly, B.C. Effect of friction fatigue on pile capacity in dense sand. J. Geotech. Geoenviron. Eng. 2007, 133, 63-71. [CrossRef]

8. Di Benedetto, H.; de La Roche, C.; Baaj, H.; Pronk, A.; Lundstrom, R. Fatigue of bituminous mixtures. Mater. Struct. 2004, 37, 202-216. [CrossRef]

9. Głuchowski, A. Permanent strain behavior of cyclically loaded cohesive soil in undrained conditions. In Proceedings of the 25th European Young Geotechnical Engineers Conference, Bucharest, Romania, 15-24 June 2016; pp. 53-60.

10. Vucetic, M.; Mortezaie, A. Cyclic secant shear modulus versus pore water pressure in sands at small cyclic strains. Soil Dyn. Earthq. Eng. 2015, 70, 60-72. [CrossRef]

11. Brown, S.F.; Yu, H.S.; Juspi, S.; Wang, J. Validation experiments for lower-bound shakedown theory applied to layered pavement systems. Géotechnique 2012, 62, 923-932. [CrossRef]

12. Głuchowski, A.; Szymański, A.; Sas, W. Repeated Loading of cohesive soil-shakedown theory in undrained conditions. Stud. Geotech. Mech. 2015, 37, 11-16. [CrossRef]

13. Tao, M.; Mohammad, L.N.; Nazzal, M.D.; Zhang, Z.; Wu, Z. Application of shakedown theory in characterizing traditional and recycled pavement base materials. J. Transp. Eng. 2010, 136, 214-222. [CrossRef]

14. Werkmeister, S. Shakedown analysis of unbound granular materials using accelerated pavement test results from New Zealand's CAPTIF facility. Geotech. Spec. Publ. 2006, 154, 220-228.

15. Cerfontaine, B.; Collin, F.; Charlier, R. Numerical modelling of transient cyclic vertical loading of suction caissons in sand. Geotechnique 2015, 65, in press. [CrossRef]

16. Sas, W.; Głuchowski, A.; Soból, E.; Bakowski, J.; Szymański, A. Analysis of the multistage cyclic loading test on resilient modulus value. Ann. Wars. Univ. Life Sci.-SGGW-Land Reclam. 2016, 48, 53-65.

17. Soltani-Jigheh, H.; Soroush, A. Cyclic behavior of mixed clayey soils. Int. J. Civ. Eng. 2010, 8, 99-106.

18. Lee, C.J.; Sheu, S.F. The stiffness degradation and damping ratio evolution of Taipei Silty Clay under cyclic straining. Soil Dyn. Earthq. Eng. 2007, 27, 730-740. [CrossRef] 
19. Rahman, M.A.; Imteaz, M.; Arulrajah, A.; Disfani, M.M. Suitability of recycled construction and demolition aggregates as alternative backfilling materials. J. Clean. Prod. 2014, 66, 75-84. [CrossRef]

20. Arulrajah, A.; Piratheepan, J.; Ali, M.M.Y.; Bo, M.W. Geotechnical properties of recycled concrete aggregate in pavement sub-base applications. Geotech. Test. J. 2012, 35, 1-9. [CrossRef]

21. Safiuddin, M.; Jumaat, M.Z.; Salam, M.A.; Islam, M.S.; Hashim, R. Utilization of solid wastes in construction materials. Int. J. Phys. Sci. 2010, 5, 1952-1963.

22. Arulrajah, A.; Disfani, M.M.; Horpibulsuk, S.; Suksiripattanapong, C.; Prongmanee, N. Physical properties and shear strength responses of recycled construction and demolition materials in unbound pavement base/subbase applications. Constr. Build. Mater. 2014, 58, 245-257. [CrossRef]

23. Sas, W.; Głuchowski, A.; Szymański, A. Behavior of recycled concrete aggregate improved with lime addition during cyclic loading. Int. J. Geomate 2016, 10, 1662-1669. [CrossRef]

24. Koenders, E.A.; Pepe, M.; Martinelli, E. Compressive strength and hydration processes of concrete with recycled aggregates. Cem. Concr. Res. 2014, 56, 203-212. [CrossRef]

25. Pepe, M.; Toledo Filho, R.D.; Koenders, E.A.; Martinelli, E. Alternative processing procedures for recycled aggregates in structural concrete. Constr. Build. Mater. 2014, 69, 124-132. [CrossRef]

26. Nataatmadja, A.; Tan, Y.L. Resilient response of recycled concrete road aggregates. J. Transp. Eng. 2001, 127, 450-453. [CrossRef]

27. Poon, C.S.; Qiao, X.C.; Chan, D. The cause and influence of self-cementing properties of fine recycled concrete aggregates on the properties of unbound sub-base. Waste Manag. 2006, 26, 1166-1172. [CrossRef]

28. Arulrajah, A.; Rahman, M.A.; Piratheepan, J.; Bo, M.W.; Imteaz, M.A. Evaluation of interface shear strength properties of geogrid-reinforced construction and demolition materials using a modified large-scale direct shear testing apparatus. J. Mater. Civ. Eng. 2013, 26, 974-982. [CrossRef]

29. Van Niekerk, A.A.; Houben, L.J.M.; Molenaar, A.A.A. Estimation of mechanical behavior of unbound road building materials from physical material properties. In Proceedings of the 5th International Conference on the Bearing Capacity of Roads and Airfields, Trondheim, Norway, 6-8 May 1998; pp. 1221-1233.

30. Lekarp, F.; Isacsson, U.; Dawson, A. State of the art.II: Premanent strain response of unbound aggregates. J. Transp. Eng. 2000, 126, 76-83. [CrossRef]

31. Bozyurt, O.; Tinjum, J.M.; Son, Y.H.; Edil, T.B.; Benson, C.H. Resilient modulus of recycled asphalt pavement and recycled concrete aggregate. In Proceedings of the GeoCongress 2012, Oakland, CA, USA, 25-29 March 2012; pp. 3901-3910.

32. Stokoe, K.H., II; Isenhower, W.M.; Hsu, J.R. Dynamic properties of offshore silty samples. In Proceedings of the 12th Annual Offshore Technology Conference, Houston, TX, USA, 4-7 May 1980; p. 3771.

33. Eurokod 7 Projektowanie Geotechniczne Część 2: Rozpoznawanie i Badanie Podtoża Gruntowego; PN-EN 1997-2:2009; Polish Committee for Standardization: Warsaw, Poland, 2009.

34. Badania Geotechniczne-Badania Laboratoryjne Gruntów-Część 4: Oznaczanie Składu Granulometrycznego; Standards PKN-CEN ISO/TS 17892-4:2009; Polish Committee for Standardization: Warsaw, Poland, 2009.

35. Adams, C.A.; Apraku, E.; Opoku-Boahen, R. Effect of triaxial geogrid reinforcement on CBR strength of natural gravel soil for road pavements. J. Civ. Eng. Res. 2015, 5, 45-51.

36. Flora, A.; Lirer, S. Small strain shear modulus of undisturbed gravelly soils during undrained cyclic triaxial tests. Geotechn.Geolog. Eng. 2013, 31, 1107-1122. [CrossRef]

37. Flora, A.; Lirer, S.; Silvestri, F. Undrained cyclic resistance of undisturbed gravelly soils. Soil Dyn. Earthq. Eng. 2012, 43, 366-379. [CrossRef]

38. Strahler, A.; Stuedlein, A.W.; Arduino, P.W. Stress-strain response and dilatancy of sandy gravel in triaxial compression and plane strain. J. Geotech. Geoenviron. Eng. 2015, 142, 04015098. [CrossRef]

(c) 2016 by the authors; licensee MDPI, Basel, Switzerland. This article is an open access article distributed under the terms and conditions of the Creative Commons Attribution (CC-BY) license (http://creativecommons.org/licenses/by/4.0/). 